\title{
THE EFFECT OF GAS-PHASE DENSITY ON BUBBLE FORMATION AT A SINGLE ORIFICE IN A TWO-DIMENSIONAL GAS-FLUIDIZED BED
}

\author{
P. J. G. HUTTENHUIS, J. A. M. KUIPERS* and W. P. M. VAN SWAAIJ \\ Department of Chemical Engineering, Twente University of Technology, P.O. Box 217, 7500 AE Enschede, \\ The Netherlands
}

(First received 14 February 1996; revised manuscript received 17 June 1996; accepted 20 June 1996)

\begin{abstract}
In this study the effect of the gas-phase density on the process of bubble formation at a single orifice in a two-dimensional gas-fluidized bed has been studied experimentally and theoretically. Specifically, a detailed comparison between experimentally observed and theoretically calculated bubble growth curves has been made in the case where the density of the gas injected through the orifice $\left(\mathrm{He}\right.$ and $\left.\mathrm{SF}_{6}\right)$ differs significantly from the density of the primary fluidizing agent (air). The calculations have been carried out using an earlier developed, first principles hydrodynamic model of gas-fluidized beds which has been extended with a species conservation equation to calculate the composition of the fluidizing gas in the vicinity of the evolving bubbles. Besides, the present experimental and theoretical results were compared with predictions obtained from adapted versions of approximate bubble formation models previously reported in the literature. The advanced hydrodynamic model appears to predict the experimentally observed diameters satisfactorily. In addition, the model correctly predicts the effect of the gas-phase density on the experimentally observed bubble growth. This effect can be explained satisfactorily in terms of the dependence of the interphase momentum transfer coefficient on gas-phase density. Finally, calculations with a three-dimensional version of our hydrodynamic model have been carried out to account for the effect of the front and back wall of the pseudo two-dimensional gas-fluidized bed used in our experiments. Our preliminary computational results indicate that the magnitude of the wall effect strongly depends on the boundary condition enforced for the gas-solid dispersion at these walls. In the case that the no-slip boundary condition was enforced in the calculations for the solid phase, the wall effect was significant and a considerable deviation between computed and experimentally observed bubble growth curves was found. However, when a more realistic partial slip boundary condition for the solid phase was implemented the agreement between theory and experiment could be improved by altering the slip parameter in the partial slip boundary condition expression. Copyright (C) 1996 Elsevier Science Ltd
\end{abstract}

Keywords: Bubble formation, gas-phase density effect, two-fluid simulation.

\section{INTRODUCTION}

The formation of gas bubbles is one of the most characteristic phenomena of fluidized beds and it has been noticed from the inception of fluidized-bed technology that many unique properties of fluidized beds can be related directly to the presence of bubbles and are dominated by their behaviour. Therefore, accurate prediction of bubble characteristics is of crucial importance for understanding and designing gas-fluidized beds. However, these characteristics depend on the 'initial' bubble characteristics at the gas distributor, where the bubbles are generated. Thus, the engineer is confronted with the necessity to understand the phenomenon of bubble formation at the gas distributor.

Furthermore, it is now widely recognized that the gas-solids contacting efficiency of fluidized-bed chemical reactors is quite sensitive to the bed hydrodynamics just above the gas distributor plate. Especially when fast heterogeneously catalysed chemical reactions are encountered, a disproportionate amount of chemical reaction occurs in the grid zone, indicating

\footnotetext{
* Corresponding author.
}

good gas-solid mass transfer characteristics between gas bubbles emanating from the distributor and the surrounding particulate phase. The relatively high degree of chemical conversion is due to the occurrence of leakage during the evolution of bubbles at the gas distributor and has been analysed theoretically by Yates et al. (1984). Their model is based on the assumption that a large part of the gas which ultimately forms a bubble (with its restricted mass transfer to the particles) leaks first to the emulsion phase for a brief period during which, in case of a fast reaction, significant chemical conversion occurs. Although the model of Yates et al. (1984) has not been tested widely against experimental data, it offers an elegant qualitative explanation for the aforementioned phenomenon and demonstrates the importance of taking gas leakage into account.

In large scale gas-fluidized beds, normally, bubbles originate from discrete holes or other orifices in the gas distributor plate on which the bed rests. Bubble formation in gas-fluidized beds at discrete orifices has been studied experimentally as well as theoretically by a number of investigators. Several approximate models, based on a strongly idealized picture of the 
process of bubble formation, have been presented in the literature and will be briefly reviewed in the next section. The process of bubble formation under conditions where the gas injected through the orifice differs significantly from the gas already present in the bed is encountered in many practical applications involving fluidized-bed chemical reactors but has not yet been studied in detail.

The main objective of this study is the expansion of our previous experimental and theoretical work (Kuipers et al., 1991; Nieuwland et al., 1996) to examine the effect of the gas-phase density on the process of bubble formation at a single orifice in a two-dimensional gas-fluidized bed. Specifically, bubble growth has been studied in the case where the density of the secondary gas injected through the orifice $\left(\mathrm{He}\right.$ or $\left.\mathrm{SF}_{6}\right)$ differs significantly from the density of the primary fluidizing agent (air). Thereby two conceivable limiting situations are simulated: one in which the density of the secondary gas is significantly lower than the primary fluidizing agent and one where the situation is reversed. In addition, the theoretical and experimental results will be compared with predictions obtained from adapted versions of approximate bubble formation models previously reported in the literature.

In practically all studies in which two-fluid simulations have been reported so far, two-dimensional hydrodynamic models were used (Gidaspow and Ettehadieh, 1983; Gidaspow, 1986; Ding and Gidaspow, 1990; Kuipers et al., 1991; Nieuwland et al., 1996). Gidaspow and Ettehadieh (1983), Kuipers et al. (1991) and Nieuwland et al. (1996) compared experimentally observed bubble sizes with those obtained from two-dimensional two-fluid simulations and reported good agreement between theory and experiment. Ding and Lyczkowski (1992) reported computations for a rectangular fluidized bed with an obstacle using both a two-dimensional and a threedimensional hydrodynamic model and found significant differences between computed time-averaged distributions of porosity and solids velocity obtained from the two-dimensional and three-dimensional models. Despite the fact that no detailed comparison with experimental data was made in this study, the necessity of three-dimensional hydrodynamic modelling was claimed.

As mentioned before, in our previous studies, the effect of the front and back confining walls of the two-dimensional fluidized bed was not accounted for in the theoretical model due to its two-dimensional nature. The assessment of this 'wall effect' on the bubble growth process, inherent in the application and related hydrodynamic modelling of two-dimensional gas-fluidized beds, constitutes a separate purpose of this work.

\section{APPROXIMATE BUBBLE FORMATION MODELS}

Fluidized beds possess a number of fluid-like properties which led Harrison and Leung (1961) to use the analogy between bubble formation in liquids and fluidized solid particles. They applied the Davidson and Schüler (1960) model, originally developed to describe spherical bubble formation at a single orifice in an inviscid liquid, to predict the size of gas bubbles emanating from a single injection point in a gasfluidized bed. According to the Davidson and Schüler model the bubble volume $V_{b}$ at detachment and the corresponding time for bubble formation $t_{b}$ ('bubble detachment time') are given, respectively, by

$$
V_{b}=1.725\left(C_{0}\right)^{0.6}\left(\frac{Q^{1.2}}{g^{0.6}}\right)
$$

and

$$
t_{b}=V_{b} / Q
$$

where $C_{0}$ represents the virtual mass coefficient of a sphere, $g$ the acceleration of gravity and $Q$ the constant gas flow rate through the orifice. The value of the virtual mass coefficient $C_{0}$ is geometry dependent (Davidson and Harrison, 1963; Milne-Thompson, 1960) and has been calculated for a number of relatively simple configurations of practical interest. This coefficient accounts for the inertia force of the solid phase which the bubble experiences during its growth. In the model used by Harrison and Leung, it is implied that no gas exchange between the bubble and the surrounding emulsion phase takes place. There is, however, substantial experimental evidence (Nguyen and Leung, 1972; Rowe et al., 1979; Yang et al., 1984; Kuipers et al., 1991; Nieuwland et al., 1996) which indicates that during the process of bubble growth, significant gas leakage from the bubble to the emulsion phase takes place. Especially for coarse particles, which possess a relatively high incipient fluidization velocity, a large amount of the gas injected through the orifice leaks to the dense phase and consequently does not visibly appear as a bubble.

In the literature several approximate bubble formation models with varying degrees of complexity have been proposed to describe the bubble formation process at a single orifice in a gas-fluidized bed. This process is schematically shown in Fig. 1. The approximate models are usually based on a mass and a momentum balance for the bubble which are, respectively, given by

$$
\begin{gathered}
\frac{\mathrm{d}}{\mathrm{d} t}\left[\rho_{f, b} V_{b}\right]=Q \rho_{f, o}-U_{e} A_{b} \rho_{f, b} \\
\frac{\mathrm{d}}{\mathrm{d} t}\left[C_{0} \rho_{e} V_{b}\left(\frac{\mathrm{d} S}{\mathrm{~d} t}\right)\right]=\rho_{e} V_{b} g
\end{gathered}
$$

In eq. (3), $A_{b}$ and $V_{b}$ denote, respectively, the surface and volume of the bubble, $Q$ and $\rho_{f, o}$ the volumetric flow rate and the density of the gas injected through the orifice, $\rho_{f, b}$ the density of the gas inside the bubble and $U_{e}$ the superficial leakage velocity, whereas in eq. (4), $\rho_{e}$ represents the emulsion phase density, $S$ the vertical distance between the bubble centre and the distributor plate and $C_{0}$ the virtual mass coefficient. 
Table 1. Overview of approximate bubble formation models presented in the literature

\begin{tabular}{lccc}
\hline Model & Bubble mass balance & Bubble momentum balance & Expression for $U_{e}$ \\
\hline Harrison and Leung (1961) & + & + & $U_{e}=0$ \\
Zenz (1968) & + & + & $U_{e}=u_{m f}$ \\
Caram and Hsu (1986) & + & + & $U_{e}=\frac{u_{m f}}{g}\left[\frac{1}{R}\left(\frac{\mathrm{d} R}{\mathrm{~d} t}\right)^{2}+\frac{\mathrm{d}^{2} R}{\mathrm{~d} t}\right]$ \\
Pierrat and Caram (1992) & + & + & + \\
\hline
\end{tabular}

${ }^{\dagger}$ Based on the reduced two-fluid mass and momentum equations for the solid phase.

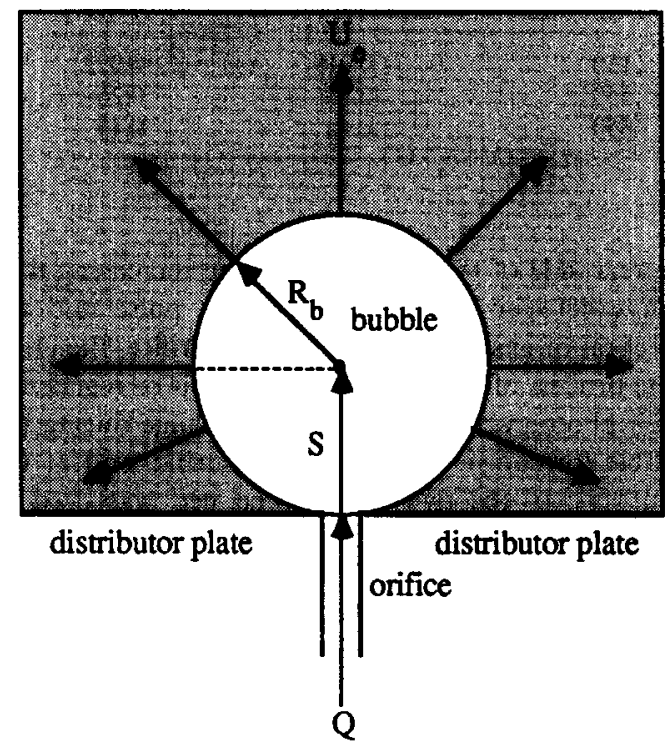

Fig. 1. Schematic representation of the process of bubble formation at a single orifice in gas-fluidized beds.

The major characteristics and the appropriate expressions for $U_{e}$ of the previously proposed approximate bubble formation models are presented in Table 1. Note that all these models assume a uniform leakage velocity over the bubble surface, although in reality it is more complex. The expression for $U_{e}$ listed in Table 1 for the Caram and Hsu (1986) model has been derived by Nieuwland et al. (1996) for a two-dimensional geometry; for a three-dimensional geometry the first term between the square brackets should be multiplied by $\frac{3}{2}$. Although the model developed by Pierrat and Caram (1992) does not fit into the mathematical formulation of eqs (3) and (4), it has been added for the sake of completeness.

As indicated before, in this study we will focus on bubble formation in situations where the density of the secondary gas injected through the orifice ( $\mathrm{He}$ or $\mathrm{SF}_{6}$ ) differs from the density of the primary fluidizing gas (air). In terms of the first three models listed in Table 1, the following species a mass balance is required in addition to eqs (3) and (4) to describe the composition changes in the evolving bubble:

$$
\frac{\mathrm{d}}{\mathrm{d} t}\left[x_{a, b} \rho_{f, b} V_{b}\right]=Q x_{a, o} \rho_{f, a}-U_{e} A_{b} x_{a, b} \rho_{f, b}
$$

where $x_{a, b}$ and $x_{a, o}$ denote, respectively, the mass fraction of species $a$ inside the bubble and the mass fraction of species $a$ in the secondary gas stream. In the expression for $U_{e}$ (see Table 1) the minimum fluidization velocity has to be calculated in accordance with the actual (i.e. corresponding to the instantaneous composition) gas-phase density inside the bubble.

\section{EXPERIMENTAL}

\subsection{Equipment and experimental procedure}

The experiments were carried out in a thin twodimensional gas-fluidized bed shown schematically in Fig. 2. Although it is possible to operate our gasfluidized bed at elevated pressure (up to 20 bar), all experiments reported in this paper were conducted at atmospheric pressure. Our equipment consists of a fluidized-bed section built of $0.005 \mathrm{~m}$ thick glass plates (internal bed dimensions: width $0.20 \mathrm{~m}$, height $0.30 \mathrm{~m}$ and depth $0.015 \mathrm{~m}$ ) and a stainless-steel gas distributor section of $0.005 \mathrm{~m}$ thick stainless steel. Humidified fluidizing air was introduced through a porous plate (sintered stainless steel, average pore size $20 \mu \mathrm{m}$ ) provided with a central rectangular pipe (internal dimensions $15.0 \mathrm{~mm} \times 15.0 \mathrm{~mm}$ ). Humidification of the primary fluidizing air was applied to reduce electrostatic charging of the bed. The relative humidity of the air was monitored during the experiments and was typically $70 \%$. Through the central rectangular pipe, covered with a stainless-steel wire mesh, the secondary fluidizing agent $\left(\mathrm{He}\right.$, air or $\left.\mathrm{SF}_{6}\right)$ could be injected independently. Calibrated thermal mass flow controllers were used to ensure constant mass flow rates of both the primary and secondary fluidizing gases. Application of rapidly responding magnetic valves coupled to a micro-computer, allowed injection of accurately known quantities of the secondary fluidizing agent (i.e. $\mathrm{He}$, air or $\mathrm{SF}_{6}$ ) through the central pipe. A hot wire anemometer, inserted in the empty bed just above the central pipe, was used to determine the time delay due to the switching of the magnetic valves. The time delay was obtained by monitoring the electrical signal of the anemometer as a function of time with the aid of a PC. A typical value of the time delay obtained in this way was $20 \mathrm{~ms}$.

During the experiments, the outflow opening at the top of the fluidized-bed section was covered with a stainless-steel wire mesh to prevent particle carry 


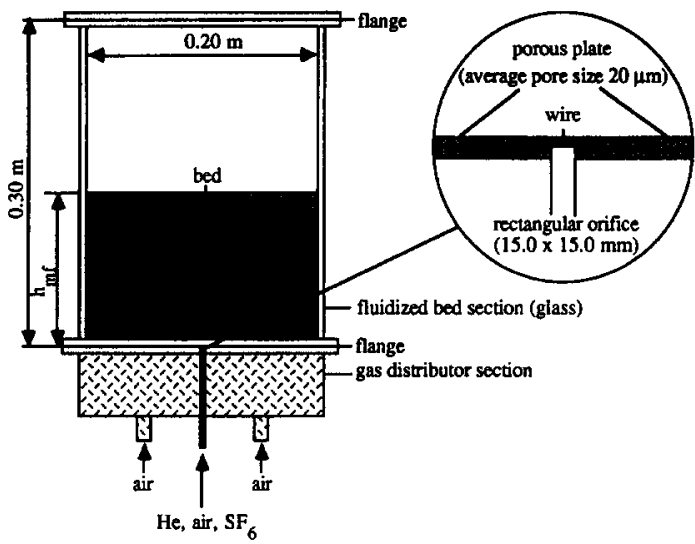

Fig. 2. Schematic representation of the two-dimensional gas-fluidized bed used in the experiments.

over from the bed and was exposed to the atmosphere. The relevant physical properties of the fluidizing gases are listed in Table 2. In this study, narrow size range spherical glass beads $\left(\rho_{s, o}=2930 \mathrm{~kg} / \mathrm{m}^{3}\right)$ with average particle diameters of $d_{p}=150,550$ and $850 \mu \mathrm{m}$ were used as the bed material. Table 3 shows a comparison between experimental $\left(u_{m f, e}\right)$ and theoretical $\left(u_{m f, t}\right)$ minimum fluidization velocities for the indicated particle diameters. The minimum fluidization velocity $u_{m}$ was obtained in the usual way by determining the point of intersection of the bed pressure drop vs fluidizing velocity curves for fixed-bed and fluid-bed flow regime, whereas the theoretical values were computed from

$$
\begin{aligned}
u_{m f}= & \frac{\mu_{f}}{d_{p} \rho_{f}} \\
& \times\left[\sqrt{33.7^{2}+0.0408 \frac{\rho_{f}\left(\rho_{s}-\rho_{f}\right) g d_{p}^{3}}{\mu_{f}^{2}}}-33.7\right] .
\end{aligned}
$$

In a typical experiment to study bubble formation, initially both the primary and secondary gas stream were injected at minimum fluidization velocity by two separate flow controllers while a third flow controller was purging the gas stream required to generate a bubble at the central orifice. By an appropriate micro-computer controlled switching of a carefully selected combination of magnetic valves, the injection velocity of the secondary stream could be increased nearly stepwise from the minimum fluidization velocity $u_{m f}$ to the desired injection velocity $u_{o}$ through the orifice at the beginning of each experiment.

\subsection{Measurement of bubble properties}

Photography has been applied as a technique to measure bubble sizes during the process of bubble formation at the central orifice. A NIKON F301 camera was used together with an ILFORD PANF ISO100 film. With the aid of a micro-computer, a pulse was generated which triggered the camera to take a photograph of the bed while a flashlight was generated at
Table 2. Physical properties of fluidizing gases

\begin{tabular}{llcc}
\hline Gas & $\begin{array}{c}\rho_{f} \\
\left(\mathrm{~kg} / \mathrm{m}^{3}\right)\end{array}$ & $\begin{array}{c}\mu_{f} \\
(\mathrm{~kg} / \mathrm{m} \mathrm{s})\end{array}$ & $\begin{array}{c}D_{a b} \\
\left(\mathrm{~m}^{2} / \mathrm{s}\right)\end{array}$ \\
\hline $\mathrm{He}$ & 0.1664 & $2.00 \times 10^{-5}$ & $6.99 \times 10^{-5}$ \\
$\mathrm{Air}$ & 1.198 & $1.81 \times 10^{-5}$ & - \\
$\mathrm{SF}_{6}$ & 6.078 & $1.53 \times 10^{-5}$ & $8.74 \times 10^{-6}$ \\
\hline
\end{tabular}

Table 3. Theoretical and experimental minimum fluidization velocities

\begin{tabular}{lll}
\hline $\begin{array}{l}d_{p} \\
(\mu \mathrm{m})\end{array}$ & $\begin{array}{l}u_{m f, e} \\
(\mathrm{~m} / \mathrm{s})\end{array}$ & \begin{tabular}{l}
$u_{m f, z}(\mathrm{~m} / \mathrm{s})$ \\
\hline 150
\end{tabular} \\
550 & 0.019 & 0.022 \\
850 & 0.26 & 0.26 \\
\hline
\end{tabular}

the rear side of the bed. By applying increasing time delays between the generation of a pulse and the injection of gas through the central orifice, the complete process of bubble formation could be registered. Each photograph shows a different stage during the bubble formation process. A measuring grid at the front side of the two-dimensional bed was used to determine the size of the bubbles from the photographs. The equivalent bubble diameter $D_{e}$ was calculated from the measured projected bubble area $A$ using the following equation:

$$
D_{e}=\sqrt{\frac{4}{\pi} A} .
$$

The reported average bubble diameters are based on two or more bubbles for each time delay used in the experiments. Typically the relative deviation between the bubble diameters found in two successive experiments was $5 \%$.

\section{HYDRODYNAMIC MODEL}

Our previously developed theoretical model of gasfluidized beds (Kuipers et al., 1992) is based on a twofluid description in which both phases are considered to be continuous and fully interpenetrating. The equations employed in this model can be seen as a generalization of the Navier-Stokes equations for two interacting continua. For the purpose of the present study, the original model has been extended to incorporate a species conservation equation to calculate the composition of the fluidizing gas in the vicinity of the evolving bubbles. The governing equations describing the two-phase flow are listed in Table 4 whereas the constitutive equations are summarized in Table 5. In the present study, bubble formation in a cold-flow two-dimensional gas-fluidized bed will be studied, and because of the anticipated small heat effects, the solution of the thermal energy equations is not considered here. The solution procedure of the species conservation equation is similar to the procedure adopted in the original model to solve the thermal 
Continuity equations

Fluid phase

$$
\frac{\partial\left(\varepsilon \rho_{f}\right)}{\partial t}+\left(\nabla \cdot \varepsilon \rho_{f} \bar{u}\right)=0
$$

Solid phase

$$
\frac{\partial\left((1-\varepsilon) \rho_{s}\right)}{\partial t}+\left(\nabla \cdot(1-\varepsilon) \rho_{s} \bar{v}\right)=0
$$

Momentum equations

Fluid phase

$$
\begin{aligned}
\frac{\partial\left(\varepsilon \rho_{f} \bar{u}\right)}{\partial t}+\left(\nabla \cdot \varepsilon \rho_{f} \bar{u} \bar{u}\right)= & -\varepsilon \nabla p-\beta(\bar{u}-\bar{v})+\left(\nabla \cdot \varepsilon\left\{\left(\lambda_{f}-{ }_{3}^{2} \mu_{f}\right)(\nabla \cdot \bar{u}) I\right\}\right) \\
& +\left(\nabla \cdot \varepsilon\left\{\mu_{f}\left((\nabla \bar{u})+(\nabla \bar{u})^{\mathrm{T}}\right)\right\}\right)+\varepsilon \rho_{f} \bar{g}
\end{aligned}
$$

Solid phase

$$
\begin{aligned}
\frac{\partial\left((1-\varepsilon) \rho_{s} \bar{v}\right)}{\partial t}+\left(\nabla \cdot(1-\varepsilon) \rho_{s} \bar{v} \bar{v}\right)= & -(1-\varepsilon) \nabla p-\beta(\bar{u}-\bar{v})+\left(\nabla \cdot(1-\varepsilon)\left\{\left(\lambda_{s}-\frac{2}{3} \mu_{s}\right)(\nabla \cdot \bar{v}) I_{j}\right\}\right) \\
& +\left(\nabla \cdot(1-\varepsilon)\left\{\mu_{s}\left((\nabla \bar{v})+(\nabla \bar{v})^{\mathbf{T}}\right)\right\}\right)-\nabla p_{s}+(1-\varepsilon) \rho_{s} \bar{g}
\end{aligned}
$$

Continuity equation species $a$

Fluid phase

$$
\frac{\partial}{\partial t}\left(\varepsilon \rho_{f} x_{a}\right)+\left(\nabla \cdot \varepsilon \rho_{f} \bar{u} x_{a}\right)=\left(\nabla \cdot \varepsilon \rho_{f} D_{e, a b} \nabla x_{a}\right)+S_{a}
$$

energy equations. For details the reader is referred to Kuipers et al. (1993).

\subsection{Numerical simulation}

4.1.1. Two-dimensional model. Figure 3 shows the initial and boundary conditions, used for the numerical simulation of bubble formation in a cold-flow two-dimensional gas-fluidized bed. The corresponding numerical data are listed in Table 6 . In all computations, we assumed the minimum fluidization condition as the initial condition. At zero time the secondary fluidizing agent $\left(\mathrm{He}\right.$, air or $\mathrm{SF}_{6}$ ) was injected through the central orifice with a constant superficial velocity $u_{o}$ of $2.0 \mathrm{~m} / \mathrm{s}$. To save computer time, symmetry about the centre line of the bed $(x=0)$ was assumed which is consistent with the symmetrical initial and boundary conditions. In the actual calculations, only the region right of the bed centre line was considered (required number of computational cells: $40 \times 100=4000$ ) with a fictitious impermeable free slip rigid wall for both phases at $x=0$ (i.e. the centre line of the bed).

4.1.2. Three-dimensional model. For the computations using the three-dimensional hydrodynamic model, the computational grid in the $x y$-plane and associated boundary conditions were identical to the two-dimensional case. In the $z$-direction six computational cells, with $z$-dimension of $0.0025 \mathrm{~m}$, were used to match the thickness of the pseudo two-dimensional bed $(0.015 \mathrm{~m})$. The total number of (interior) computational cells for the three-dimensional calculations was $100 \times 40 \times 6=24,000$. In this case no symmetry assumption with respect to the central $x y$-plane in the fluidized bed was made. Table 6 summarizes the values of all important numerical data used in the calculations. In view of the uncertainty regarding the formulation of the correct boundary condition at the confining impermeable walls of the fluidized bed, three different types of boundary conditions were considered:

(a) free-slip boundaries for both phases,

(b) no-slip boundaries for both phases,

(c) no-slip boundaries for the gas phase and partial-slip boundaries for the solid phase.

The calculation for case (a) was performed as a check of the three-dimensional computer code, since in this case no effect of the front and back wall should be observed, which implies that the equivalent bubble diameter should exactly equal the value found for the corresponding two-dimensional case. Boundary conditions (b) implies the most significant momentum exchange between the gas-solid dispersion and the confining front and back wall. It is expected that the true boundary condition is intermediate between free slip and no slip and therefore also a computation with a partial slip boundary condition for the solid phase was carried out. In this computation, we used the 
Fluid-phase density

$$
\rho_{f}=\frac{p}{R T_{f}}\left[y_{a} M_{a}+\left(1-y_{a}\right) M_{b}\right]
$$

where

$$
y_{a}=\frac{\frac{x_{a}}{M_{a}}}{\frac{x_{a}}{M_{a}}+\frac{\left(1-x_{a}\right)}{M_{b}}}
$$

Solid phase density

$$
\rho_{s}=\rho_{s, o}
$$

Interphase momentum transfer coefficient $\beta$ :

For $\varepsilon>0.8$

$$
\beta=150 \frac{(1-\varepsilon)^{2}}{\varepsilon} \frac{\mu_{f}}{\left(\phi_{s} d_{p}\right)^{2}}+1.75(1-\varepsilon) \frac{\rho_{f}}{\left(\phi_{s} d_{p}\right)}|\bar{u}-\bar{v}|
$$

For $\varepsilon \leqslant 0.8$

$$
\beta=\frac{3}{4} C_{d} \frac{\varepsilon(1-\varepsilon)}{\left(\phi_{s} d_{p}\right)} \rho_{f}|\bar{u}-\bar{v}| \varepsilon^{-2.65}
$$

where

$$
\begin{array}{ll}
C_{d}=\frac{24}{R e_{p}}\left[1+0.15\left(R e_{p}\right)^{0.687}\right] & R e_{p}<1000 \\
C_{d}=0.44 & R e_{p} \geqslant 1000
\end{array}
$$

where

$$
R e_{p}=\frac{\varepsilon \rho_{f}|\bar{u}-\bar{v}| d_{p}}{\mu_{f}}
$$

Fluid-phase viscosity

$$
\mu_{f}=y_{a} \mu_{a}+\left(1-y_{a}\right) \mu_{b}
$$

Solid-phase viscosity

$$
\mu_{s}=\mu_{s, o}
$$

Solid-phase pressure

$$
p_{s}=0.01\{\exp [100(0.45-\varepsilon)]\}
$$

Effective diffusion coefficient

$$
D_{e, a b}=[1-\sqrt{(1-\varepsilon)}] D_{a b}
$$

following equations which are similar to those formulated by Ding and Gidaspow (1990):

$$
\left(\bar{v}_{t}\right)_{\text {wall }}=-\left(\lambda_{p} \frac{\partial \bar{v}_{t}}{\partial n}\right)_{\text {wall }}
$$

where $\left(\bar{v}_{t}\right)$ denotes the tangential (i.e. in the $x y$-plane) solid-phase velocity, $n$ the co-ordinate direction normal to the wall and $\lambda_{p}$ a slip parameter which can be calculated from

$$
\lambda_{p}=\frac{f d_{p}}{(1-\varepsilon)^{1 / 3}}
$$

where $f$ represents a dimensionless slip parameter which can be given a value between zero (no slip) and infinity (free slip). A value of $f=1$ corresponds to the original boundary equations of Ding and Gidaspow (1990). Note that the above formulation of the partial slip boundary condition correctly reduces to the noslip boundary condition in case the particle diameter $d_{p}$ becomes small. All computations reported in this paper have been performed on a PC. Two-dimensional calculations took approximately $24 \mathrm{~h}$ of computing time whereas the three-dimensional calculations took three weeks of computing time.

\subsection{Post processing of numerical data}

4.2.1. Two-dimensional model. Once the bubble contour has been specified in terms of the porosity, all bubble parameters such as shape and size can be 


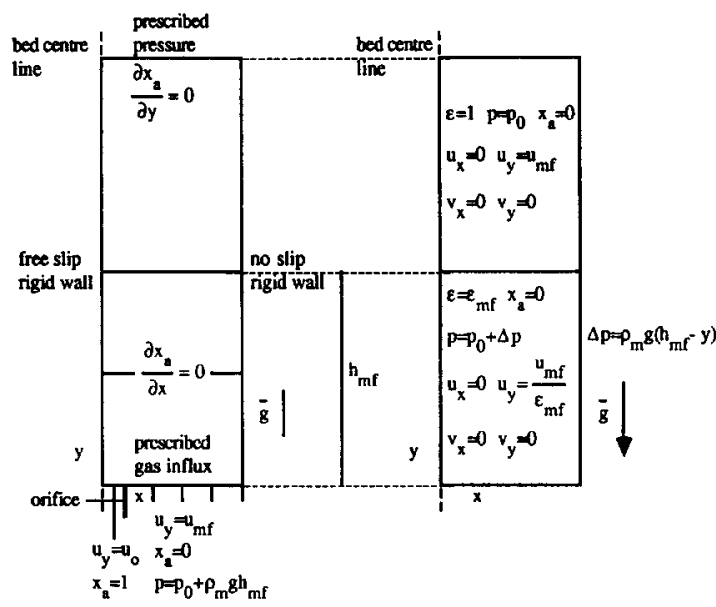

Fig. 3. Initial and boundary conditions used for the numerical simulation of bubble formation in a cold-flow two-dimensional gas-fluidized bed.

Table 6. Data used for numerical simulations

Minimum fluidization porosity

Injection velocity through orifice

Initial freeboard pressure

Bed width

Initial bed height

Two-dimensional simulations

Time step

$x$-Grid size

$y$-Grid size

Three-dimensional simulations

Time step

$x$-Grid size

$y$-Grid size

$z$-Grid size and

$$
D_{e}=\sqrt{\frac{4}{\pi} A} .
$$

4.2.2. Three-dimensional model. For the three-dimensional case, the procedure followed to obtain the equivalent bubble diameter $D_{e}$ from the calculated instantaneous porosity distribution was quite similar to the one used for the two-dimensional case. For each plane $z=(k-0.5) \delta z=$ constant $(z$ denotes the direction perpendicular to the front and back walls of the bed whereas $k$ denotes the $z$-grid index) the differential (i.e. for plane $k$ ) contribution to the bubble volume $\mathrm{d} V_{k}$ is calculated using the following straightforward extension of eq. (10):

$$
\mathrm{d} V_{k}=\sum_{i}\left(y_{t}-y_{b}\right)_{k} \delta x \delta z
$$

By summing the differential contributions $\mathrm{d} V_{k}$ with respect to all $k$-planes, the total bubble volume $V_{b}$ is obtained, from which the equivalent bubble diameter $D_{e}$ is calculated as

$$
D_{e}=\sqrt{\frac{4}{\pi} \frac{V_{b}}{\delta_{b}}}
$$

where $\delta_{b}$ is the 'bed thickness' (i.e. distance between the front and back wall). It should be noted that the familar relation between $D_{e}$ and $V_{b}$ for a spherical bubble is not useful in this case due to the presence of the front and back wall of the bed which restrains the bubble growth in the $z$-direction.

\section{RESULTS}

Prior to the presentation of the detailed experimental and theoretical results, two aspects, namely the bubble definition and the effect of the computational grid, need further attention and will be considered in more detail in the next paragraph.

\subsection{Bubble definition and effect of computational grid}

As stated earlier, the computer model produces the instantaneous porosity distribution at distinct spatial locations in the computational domain. To extract bubble parameters, such as shape and size, from these distributions, it is necessary to define the bubble contour in terms of the porosity. Figure 4 shows a number of porosity contours $(\varepsilon=0.80, \varepsilon=0.85$, and $\varepsilon=$ $0.90)$ near detached bubbles at $t=0.12 \mathrm{~s}$ for the intermediate particle size $\left(d_{p}=550 \mu \mathrm{m}\right)$ and air as secondary fluidizing gas. From Fig. 4 it can be seen that very strong porosity gradients exist near the bubble base whereas these gradients are considerably weaker near the bubble roof. Despite the fact that there exists some sensitivity with respect to the selected porosity contour defining a bubble, in the present study the $\varepsilon=0.85$ contour was taken.

Figure 5 shows the $\varepsilon=0.85$ contour of a detached bubble at $t=0.12 \mathrm{~s}\left(d_{p}=550 \mu \mathrm{m}\right.$, secondary fluidizing agent: air) computed for a grid with $\delta x=0.00250 \mathrm{~m}$ and $\delta y=0.00300 \mathrm{~m}$ and a finer grid with $\delta x=0.00125 \mathrm{~m}$

$$
A=\sum_{i}\left(y_{t}-y_{b}\right) \delta x
$$




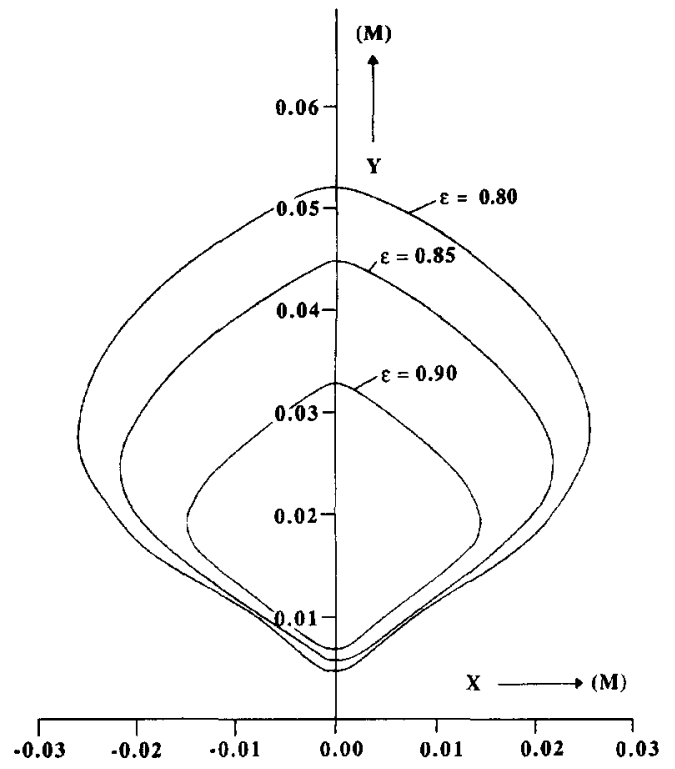

Fig. 4. Theoretically calculated porosity contours near a detached bubble at $t=0.12 \mathrm{~s}, d_{p}=550 \mu \mathrm{m}, u_{0}=2.0 \mathrm{~m} / \mathrm{s}$, secondary fluidizing gas: air.

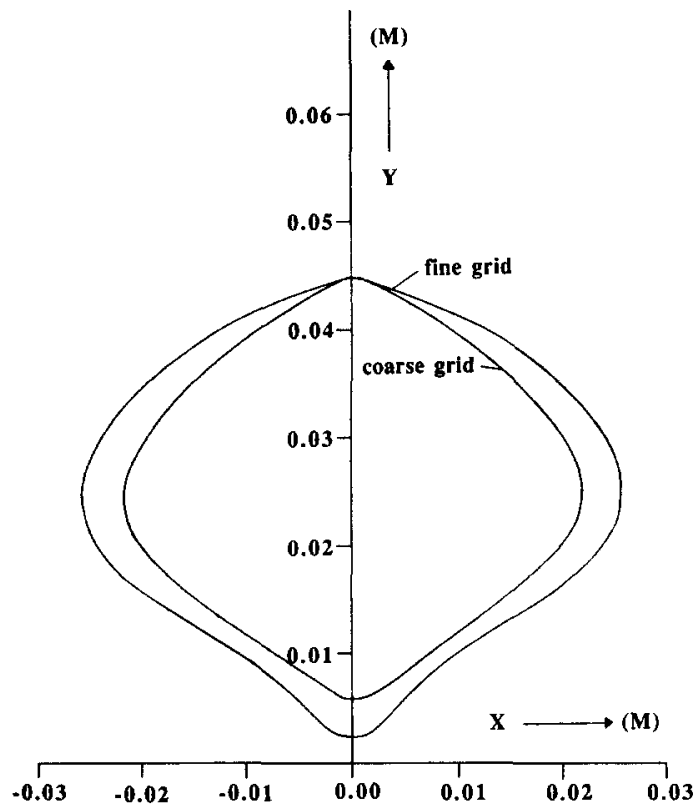

Fig. 5. Effect of computational grid on the $\varepsilon=0.85$ contour defining a bubble, $d_{p}=550 \mu \mathrm{m}, u_{0}=2.0 \mathrm{~m} / \mathrm{s}$, secondary fluidizing gas: air. 'Coarse' grid: $\delta x=0.00250 \mathrm{~m}, \delta y=$ $0.00300 \mathrm{~m}$, fine grid: $\delta x=0.00125 \mathrm{~m}, \delta y=0.00150 \mathrm{~m}$.

and $\delta z=0.00150 \mathrm{~m}$. From Fig. 5 it can be seen that small differences exist between the computational results of the 'coarse' ( 4000 cells) and 'fine' grid $(16,000$ cells) and therefore the 'coarse' grid was used for all two-dimensional simulations.

\subsection{Effect of gas-phase density on bubble formation}

Figure 6(a) shows a comparison between the theoretically calculated and experimentally determined bubble sizes as a function of time for the smallest particles $\left(d_{p}=150 \mu \mathrm{m}\right)$ and $\mathrm{He}$, air or $\mathrm{SF}_{6}$ as secondary fluidizing agent. Note that the agreement between theory and experiment is reasonable, and additionally that no significant effect of the density of the secondary gas can be observed in this case. The data shown in Fig. 6(a) can also be represented in terms of the integral leakage fraction $\Psi(t)$ defined by

$$
\Psi(t)=1-\frac{V_{b}(t)}{V_{0}(t)}
$$

where $V_{0}(t)$ represents the bubble volume corresponding to zero leakage. Figure $6(\mathrm{~b})$ shows the leakage $\Psi(t)$ curve corresponding to the data presented in Fig. 6(a). From Fig. 6(b) it can be seen that the most significant leakage occurs during the initial stage of bubble formation. Of course, the gas which does not visibly appear as a bubble is not lost but is accommodated by the emulsion phase surrounding the bubble. Since the leakage predominantly occurs through the bubble roof (Kuipers et al., 1991), it is likely that an expanded emulsion phase exists near the bubble roof. For the particles of intermediate size $\left(d_{p}=550 \mu \mathrm{m}\right)$ the bubble growth curves and the corresponding leakage curves are shown in Fig. 7(a) and (b), whereas for the large particles $\left(d_{p}=850 \mu \mathrm{m}\right)$ these curves are shown in Fig. 8(a) and (b). In contrast to the small particles, for the particles of intermediate and large size, a significant effect of the density of the secondary gas on the bubble growth process can be observed. From Figs 7 (a) and 8(a), it can be seen that for a given particle diameter, the bubble size increases with increasing density of the gas injected through the orifice. This effect can be explained by considering the dependence of the interphase momentum transfer coefficient $\beta$ on the density of the gas present inside the growing bubble. Of course the density difference between the growing gas bubble and its surroundings changes when the density of the injected gas changes, but this effect is relatively unimportant since the interphase momentum transfer term is the dominant term in the gas-phase momentum equation. For bubbles injected into a fluidized bed at incipient fluidization conditions the relevant expression for $\beta$ is given by

$$
\beta=150 \frac{(1-\varepsilon)^{2}}{\varepsilon} \frac{\mu_{f}}{\left(\phi_{s} d_{p}\right)^{2}}+1.75(1-\varepsilon) \frac{\rho_{f}}{\left(\phi_{s} d_{p}\right)}|\bar{u}-\bar{v}| .
$$

This equation shows that the interphase momentum transfer consists of two contributions of which the first term, the friction drag, is independent of gas density whereas the second term, the form drag, is dependent on gas density. For small particles, the first term on the right-hand side of eq. (15) (i.e. the friction $\mathrm{drag}$ ) is dominant and since the viscosities of $\mathrm{He}$, air and $\mathrm{SF}_{6}$ do not differ significantly (see Table 2) no effect of the secondary gas type on $\beta$ and hence on the bubble growth process is to be expected.

However, with increasing particle diameter, the relative contribution of the second term on the 

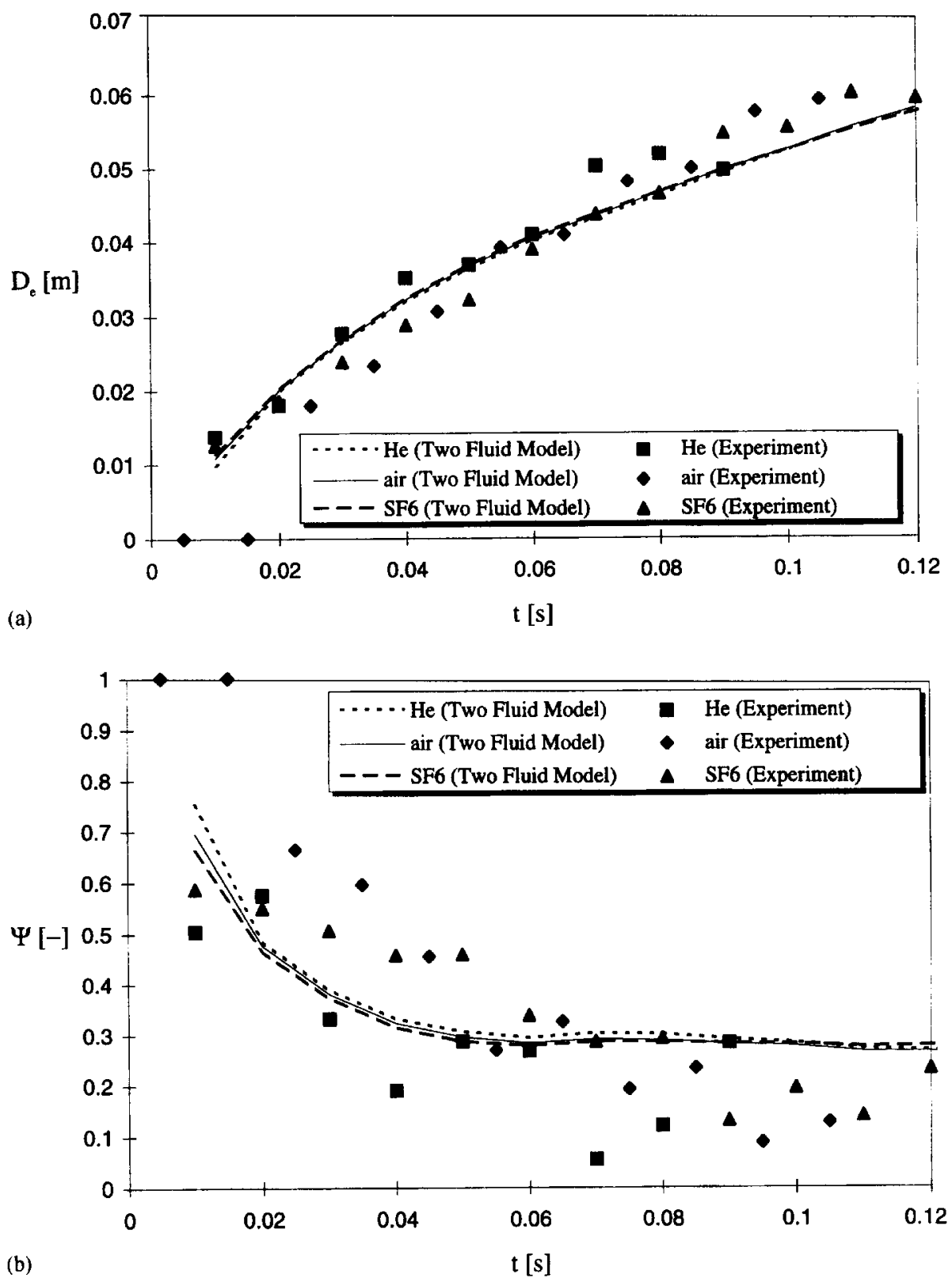

Fig. 6. Bubble growth (a) and leakage curves (b) for small particles $\left(d_{p}=150 \mu \mathrm{m}\right)$ and $\mathrm{He}$, air or $\mathrm{SF}_{6}$ as secondary fluidizing agent.

right-hand side of eq. (15) (i.e. the form drag) increases and, consequently, a change in gas-phase density will alter $\beta$ and will therefore influence the bubble growth process. The magnitude of $\beta$ increases with increasing gas-phase density, and, due to the enhanced momentum transfer between the gas percolating through the bubble boundary and the suspended particles, bubble growth is facilitated.

A similar effect was reported by Nieuwland et al. (1995) who studied bubble formation at elevated pressure. In their study, an increasing bubble size with increasing operating pressure was found. The close similarity between the effect of operating pressure and the effect of molecular weight is expected behaviour, since these quantities affect gas-phase density in a similar way. This was checked computationally, by comparing the bubble growth curve for air as secondary fluidizing agent at an operating pressure of 5 bar (corresponding to approximate ratio of molecular weight of $\mathrm{SF}_{6}$ and air) with the bubble growth curve for $\mathrm{SF}_{6}$ at an operating pressure of 1 bar. In both cases air was used as the primary fluidizing agent. In these two simulations practically identical bubble growth curves were found, especially during the initial stages of bubble formation.

Figures $9(a)$ and (b), respectively, show the bubble growth and corresponding leakage curves for the particles of intermediate size $\left(d_{p}=550 \mu \mathrm{m}\right)$ obtained 

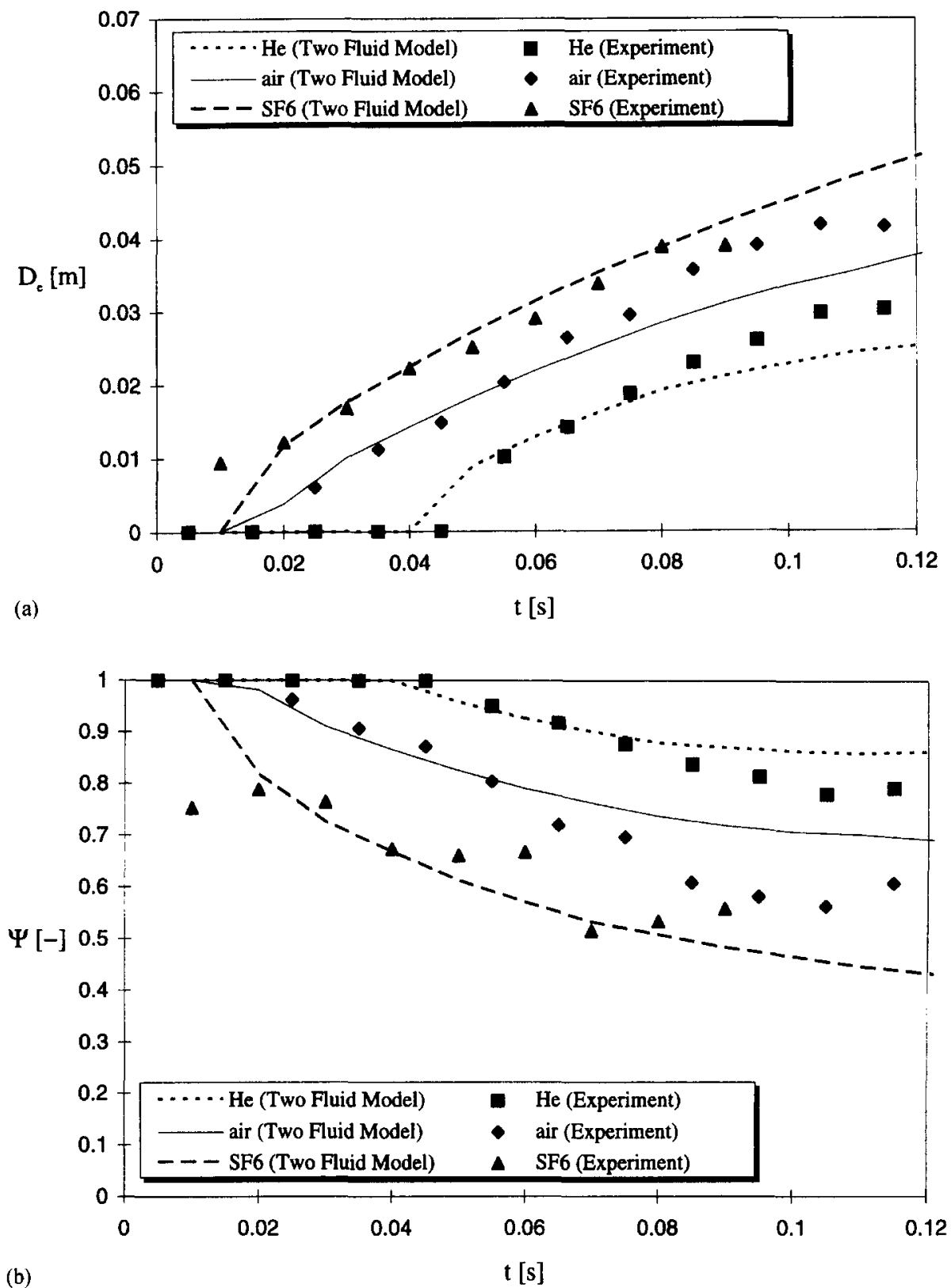

Fig. 7. Bubble growth (a) and leakage curves (b) for intermediate size particles $\left(d_{p}=550 \mu \mathrm{m}\right)$ and $\mathrm{He}$, air or $\mathrm{SF}_{6}$ as secondary fluidizing agent.

from adapted versions of the approximate bubble formation models discussed in Section 2. A fourthorder Runge-Kutta method was applied to numerically integrate the model equations (3)-(5). For the purpose of reference, the predictions obtained from the two-fluid model are included in Fig. 9(a) and (b). From this figure it can be seen that the Harrison Leung model and the Zenz model, respectively, predict the largest and smallest bubble sizes whereas the Caram and $\mathrm{Hsu}$ model predicts bubble sizes which are intermediate between those predicted from the first mentioned approximate bubble formation models. These results can be understood on basis of the differences between the expressions (see Table 1) for the superficial leakage velocity used in these models. In general, the approximate bubble formation models tend to overestimate the bubble sizes obtained from the two-fluid model especially in the case where helium is injected through the orifice.

\subsection{Effect of third dimension on computed bubble sizes}

As indicated before, the front and back walls of pseudo two-dimensional gas-fluidized beds cannot be accounted for in two-dimensional hydrodynamic models though these walls possess the highest contact area with the fluidized suspension. To study the effect of these confining walls on the bubble formation process computationally, preliminary calculations were 


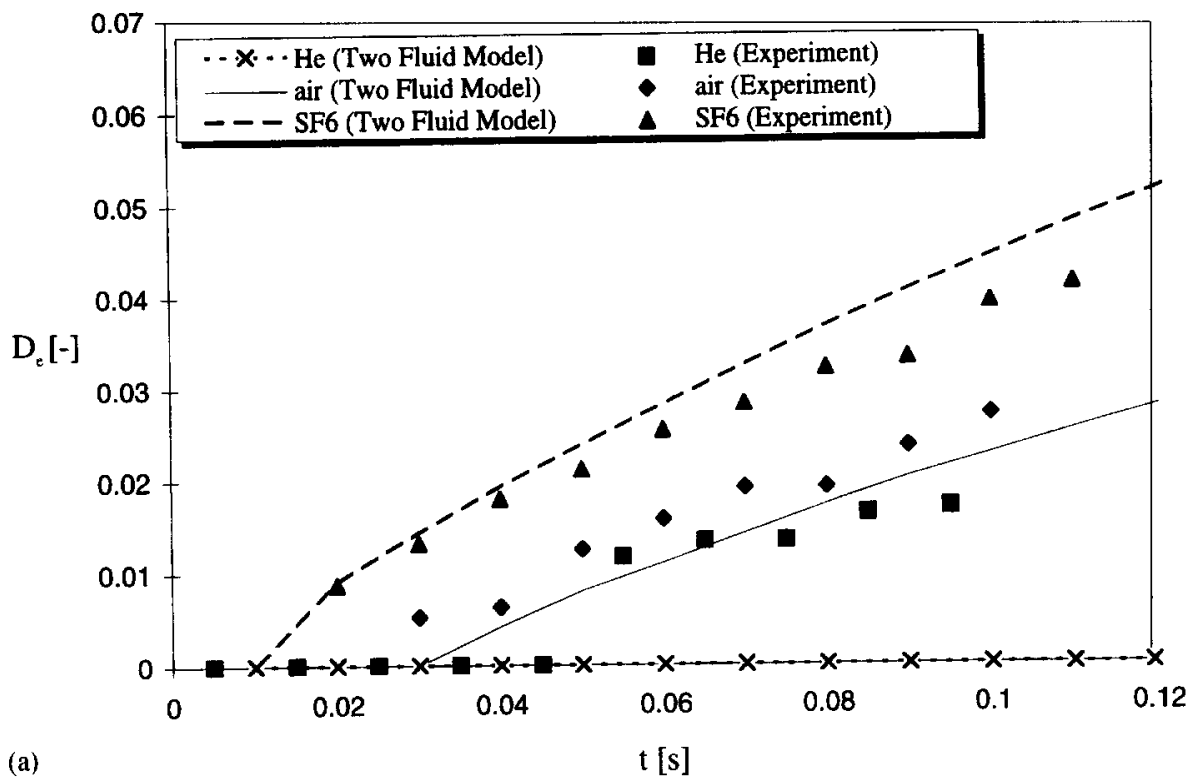

(a)

\section{$\mathrm{t}[\mathrm{s}]$}

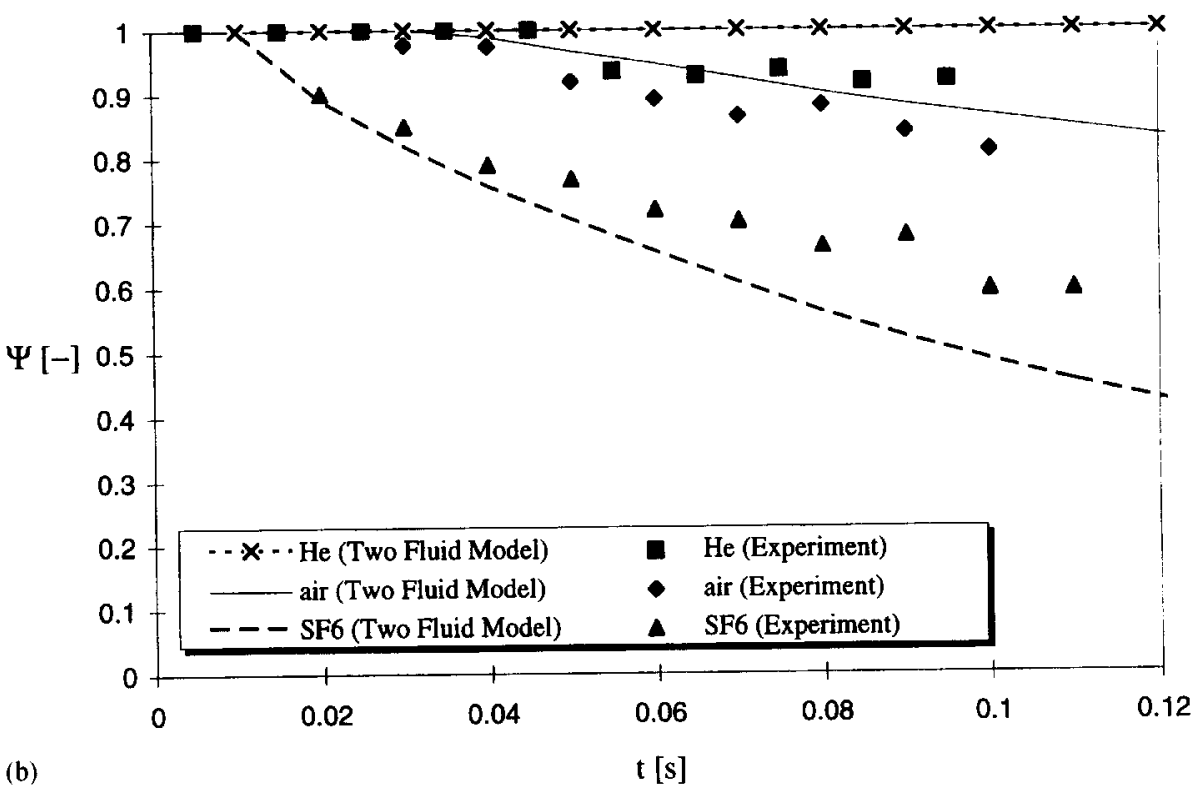

Fig. 8. Bubble growth (a) and leakage curves (b) for large particles $\left(d_{p}=850 \mu \mathrm{m}\right)$ and $\mathrm{He}$, air or $\mathrm{SF}_{6}$ as secondary fluidizing agent.

carried out for the particles of intermediate size $\left(d_{p}=\right.$ $550 \mu \mathrm{m})$ with air as the secondary fluidizing agent. First, three preliminary calculations were performed which correspond to the aforementioned boundary conditions applied for both phases at the confining walls.

Figure 10 shows the computed bubble growth curves using the three-dimensional model for the cases (a)-(c) together with the experimental data. For the purpose of reference, the results of two simulations using the two-dimensional model have been included in this figure. In one of these two-dimensional computations, the viscous interaction in the solid phase was neglected whereas in the other computation this interaction was taken into account. For the threedimensional computation case (c), the slip parameter $f$ was given a value of one. As expected, the results for case (a) coincide with the results obtained from the two-dimensional model with zero solid-phase viscosities. The three-dimensional calculation for case (a) correctly produces a solution showing no dependence in the $z$-direction. Furthermore, the three-dimensional calculations for both cases (b) and (c) yield considerably smaller bubble sizes compared to those found for case (a) and those observed experimentally. The computed bubble growth curves for cases (b) and (c) using the three-dimensional model show very small differences which implies that a slip parameter of $f=1$ in 


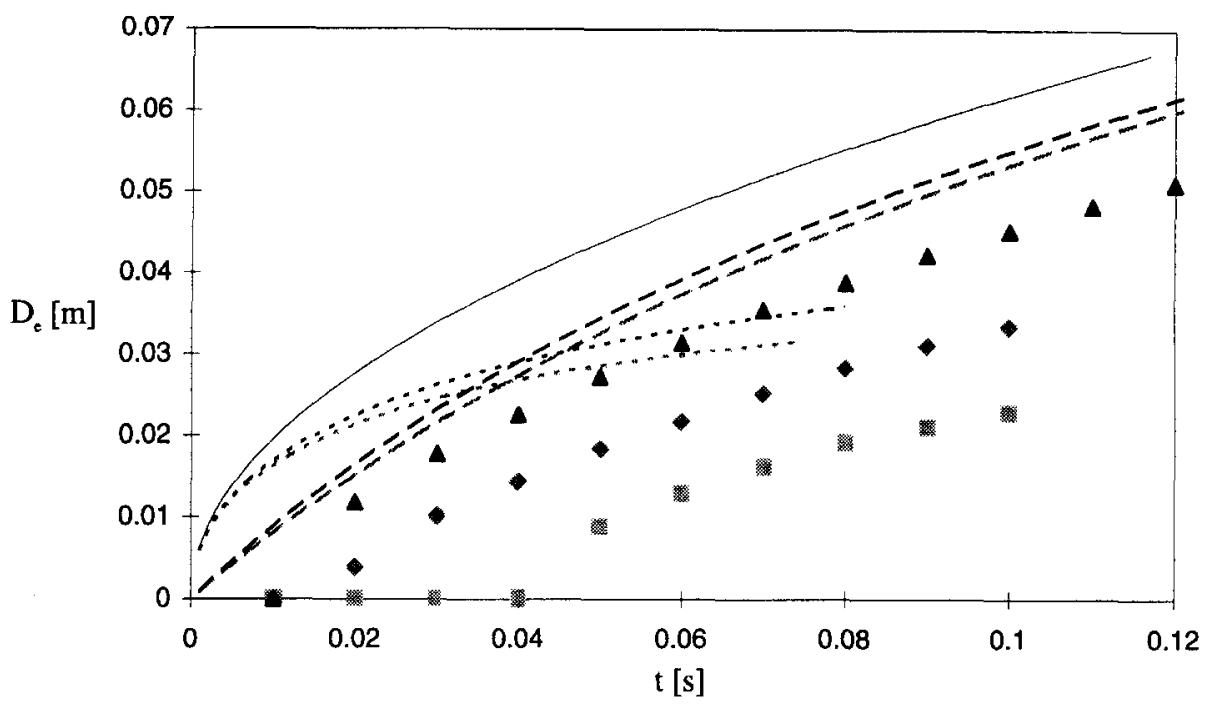

(a)

\begin{tabular}{|c|c|c|}
\hline __ Harrison Leung & $\ldots \ldots \ldots$ He (Zenz) & $\cdots \cdots$ air (Zenz) \\
\hline$\cdots \cdot$ SF6 (Zenz) & …........... He (Caram Hsu) & - - - air (Caram Hsu) \\
\hline $\begin{array}{l}-- \text { SF6 (Caram Hsu) } \\
\text { A SF6 (Two Fluid Model) }\end{array}$ & He (Two Fluid Model) & * air (Two Fluid Model) \\
\hline
\end{tabular}

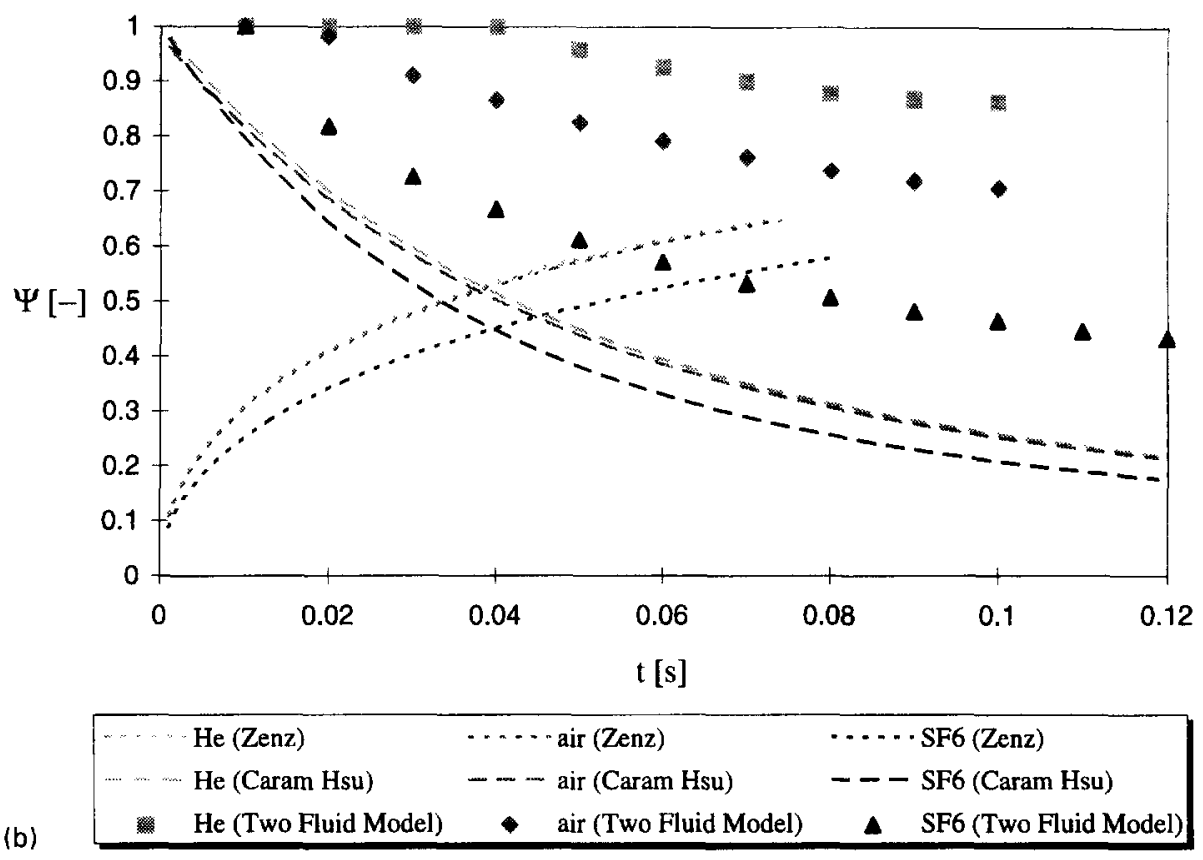

Fig. 9. A comparison between bubble growth (a) and leakage curves (b) predicted from approximate bubble formation models and two-dimensional two-fluid model for particles of intermediate size $\left(d_{p}=550 \mu \mathrm{m}\right)$ and $\mathrm{He}$, air or $\mathrm{SF}_{6}$ as secondary fluidizing agent.

fact leads to a no-slip boundary condition in this case. From this figure, it can also be seen that the experimentally observed bubble diameters fall between the predicted bubble growth curves obtained from twodimensional model and that three-dimensional hydrodynamic modelling does not 'automatically' lead to a better agreement between theory and experiment in comparison with two-dimensional hydrodynamic modelling. This outcome is due to the boundary condition enforced at the confining impermeable walls for the solid phase. Clearly the no-slip boundary condition and the partial slip boundary condition given by eqs (8) and (9) with $f=1$ leads to incorrect results. Of course the no-slip boundary condition is also applied in the two-dimensional model at the left and right confining walls (see Fig. 3) of the fluidized 
bed, but apparently the effect on the process of bubble growth at the central orifice is quite small in this case (see Fig. 10).

Figure 11 shows the computed bubble growth curves using the three-dimensional model for the boundary condition case (c) and several $f$ values $(f=0,1$ and 10) together with the experimental data. From this figure, it can be seen that increasing $f$ values, which corresponds to increased solid phase slip velocity at the wall, leads to a better agreement between the computational and experimental results. The uncertainty with respect to the correct $f$ value certainly constitutes a weak point of the present boundary condition formulation. In this respect discrete particle models, as recently presented by Hoomans et al. (1996), might provide guiding lines for the development of more

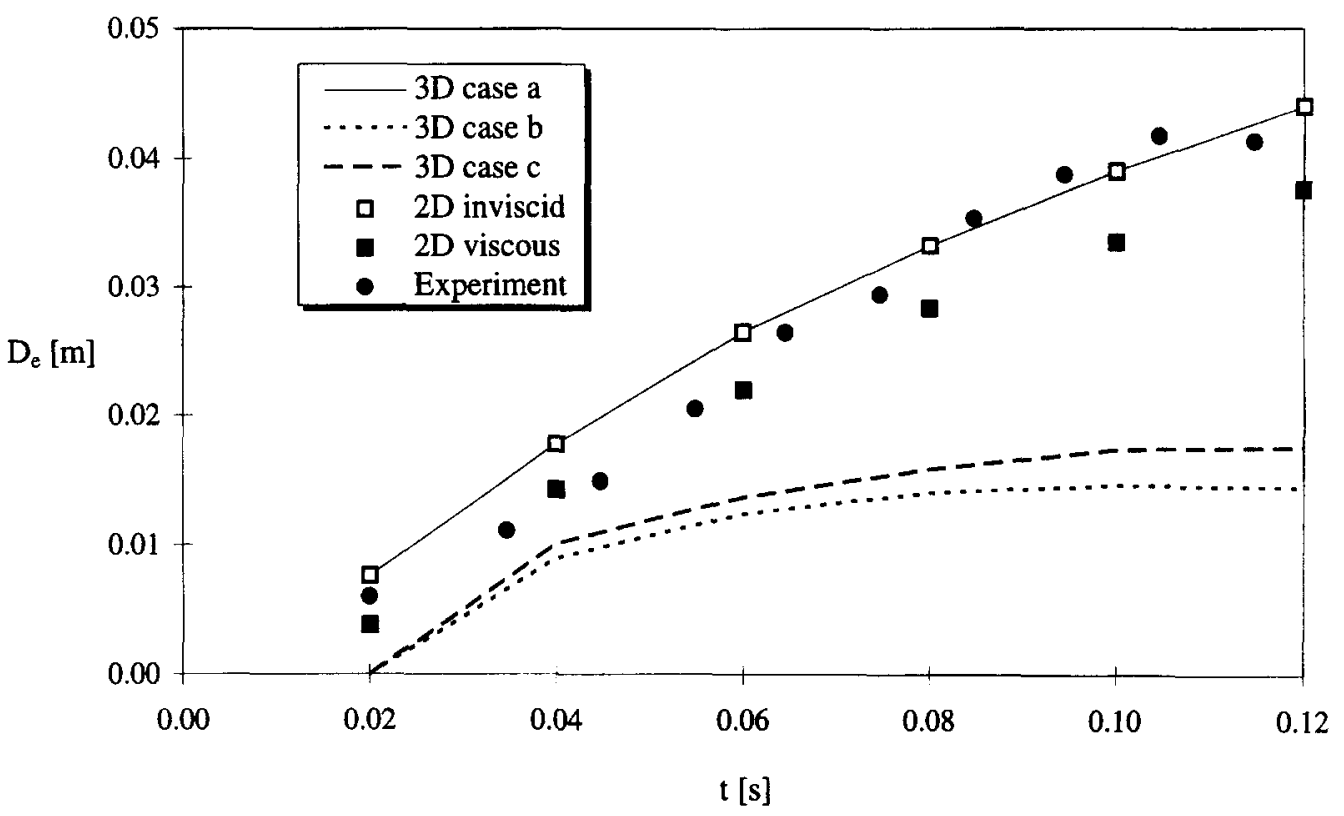

Fig. 10. Computed bubble growth curves from three-dimensional two-fluid model for particles of intermediate size $\left(d_{p}=550 \mu \mathrm{m}\right)$ and air as secondary fluidizing agent together with experimental data and predictions obtained from two-dimensional two-fluid model.

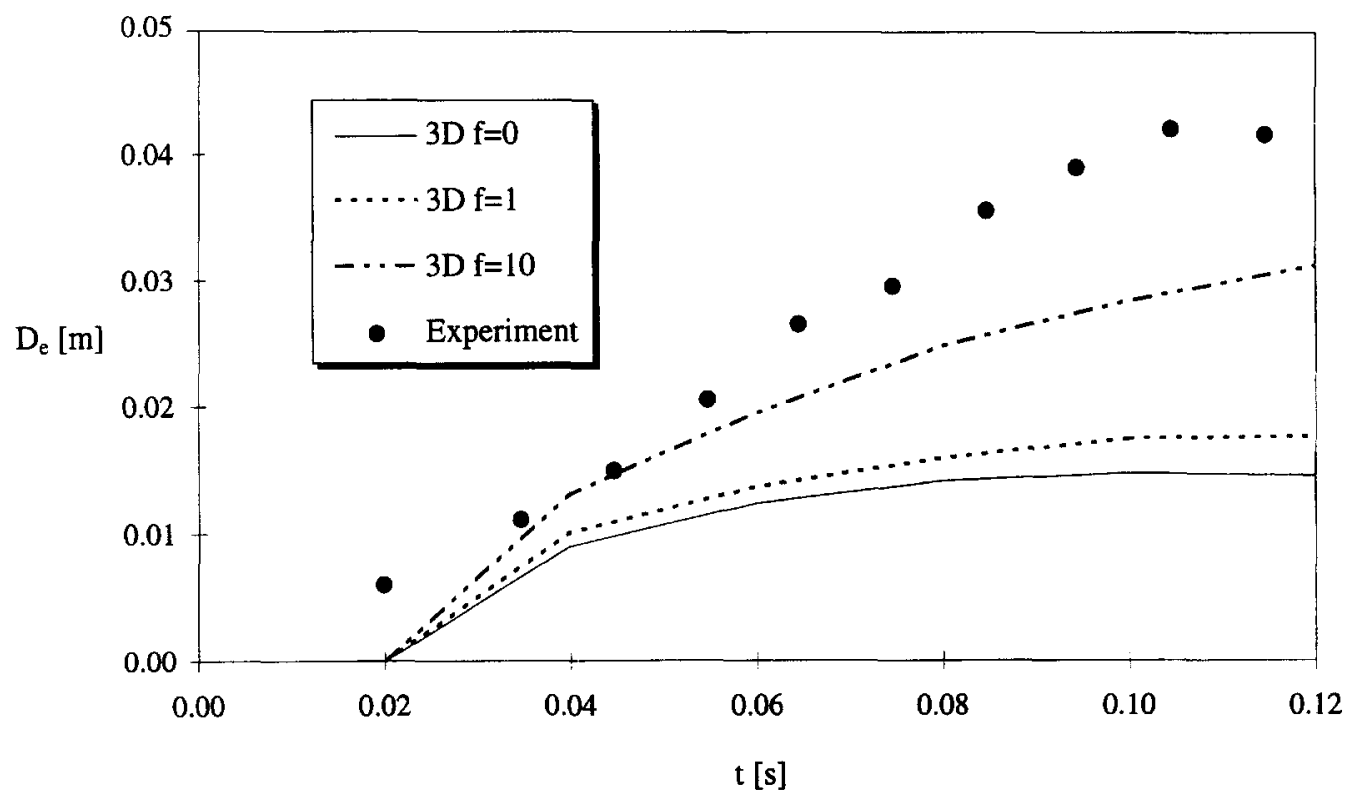

Fig. 11. Computed bubble growth curves from three-dimensional two-fluid model for particles of intermediate size $\left(d_{p}=550 \mu \mathrm{m}\right)$ with $f=0, f=1$ and $f=10$ and air as secondary fluidizing agent together with experimental data. 
general and accurate boundary condition expressions in particular, and closure laws for the solid-phase stress tensor in general.

A closer examination of the computational results, obtained in case a partial slip boundary condition was used for the solid phase, revealed that significant gradients exist in the $z$-direction. Figure 12 shows the $\varepsilon=0.85$ contour at $t=0.12 \mathrm{~s}$ [case (c)] for three different $x y$-planes for which $z=$ constant. Due to the symmetry about the $x y$-plane in the bed centre $(z=0.0075 \mathrm{~m})$, the remaining three planes are not shown here. It can clearly be seen from Fig. 12 that a small 'wall effect' exists: the bubble growth near the wall is somewhat restricted whereas this process is relatively unaffected in the $x y$-plane near the bed centre. In the case where a no-slip boundary condition for the solid phase was implemented (not shown here) this 'wall effect' was much more pronounced.

Our future work will be concerned with the extension of the experimental and theoretical work to reactive conditions. Extended versions of the present model which account for mass transfer and heterogeneous chemical conversion with associated heat effect in the solid phase are already available. Due to the enormous computational load of three-dimensional models, the application of this model type to full-scale fluidized-bed reactors is unfortunately very difficult, especially when a high spatial resolution is required to capture bubble dynamics on the smallest scale. However, in the opinion of the authors a realistic description of heterogeneously catalysed chemical conversion in the vicinity of one or more orifices ('grid zone') is clearly within the range of the present models.

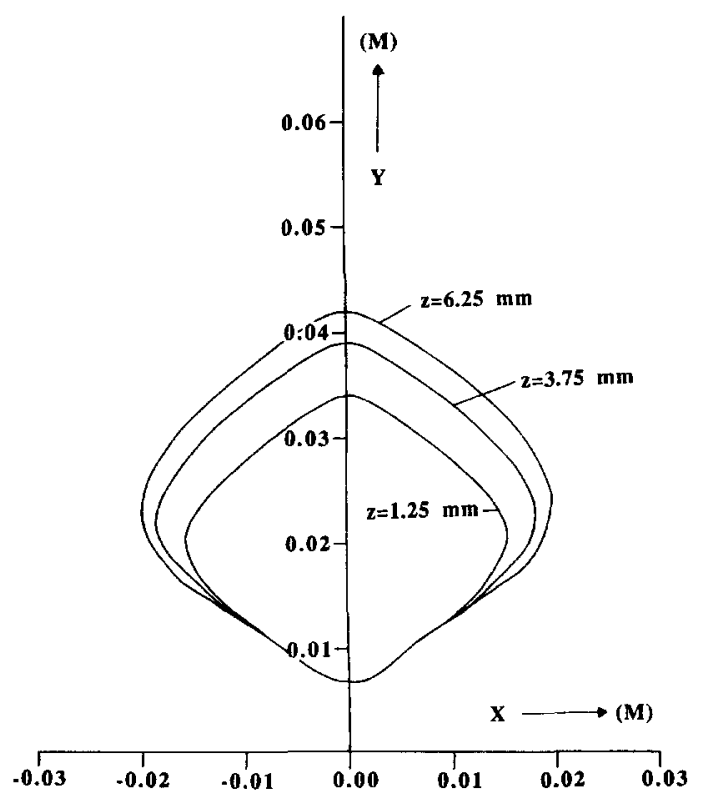

Fig. 12. Computed contour of $\varepsilon=0.85$ from three-dimensional model $(f=10)$ at three different $x y$-planes; $z=$ constant for particles of intermediate size $\left(d_{p}=550 \mu \mathrm{m}\right)$ with air as secondary fluidizing agent at $t=0.12 \mathrm{~s}$.

\section{CONCLUSIONS}

In this study, the effect of gas-phase density on the process of bubble formation at a single orifice in a two-dimensional gas-fluidized bed has been examined experimentally and theoretically. Specifically, a detailed comparison between experimentally observed and theoretically calculated bubble growth curves has been made in the case where the density of the gas injected through the orifice ( $\mathrm{He}$ and $\mathrm{SF}_{6}$ ) differs significantly from the density of the main fluidizing agent (air). The experimentally observed bubble sizes showed a satisfactory degree of agreement with predictions made using a hydrodynamic model based on the twofluid concept. The effect of gas-phase density on observed bubble sizes can fully be explained in terms of its effect on momentum transfer to the particulate phase.

Furthermore, a comparison of the experimental and theoretical data with predictions obtained from previously proposed approximate bubble formation models, has been made. These models typically assume circular (two-dimensional) or spherical (three-dimensional) bubbles and a uniform leakage velocity through the bubble surface, assumptions which are critical at, respectively, the final and the initial stage of bubble formation. Nevertheless, the approximate models clearly have their utility due to their ability to predict the correct order of magnitude of the bubble sizes.

Finally, on the basis of preliminary calculations using a three-dimensional version of our hydrodynamic model, the effect (on computed bubble sizes) of neglecting the front and back walls in two-dimensional hydrodynamic models could be assessed. In the case where the no-slip boundary condition was applied for the solid phase at the confining walls of the bed, a significant wall-effect was found, however implementation of a more realistic partial slip boundary condition showed a much smaller wall effect.

Acknowledgements - The authors acknowledge O.D. Veehof and A.H. Pleiter for their assistance in the experimental work.

$A_{b}$
$C_{0}$
$C_{d}$
$d_{p}$
$D_{e, a b}$

$D_{a b}$

$D_{e}$
$D_{h}$
$D_{v}$
$f$

\section{NOTATION}

bubble surface, $\mathrm{m}^{2}$ virtual mass coefficient, dimensionless drag coefficient, dimensionless particle diameter, $\mathrm{m}$ effective binary diffusion coefficient of species $a$ in binary mixture of species $a$ and $b, \mathrm{~m}^{2} / \mathrm{s}$

$D_{a b} \quad$ molecular binary diffusion coefficient of species $a$ in binary mixture of species $a$ and $b, \mathrm{~m}^{2} / \mathrm{s}$

equivalent bubble diameter, $\mathrm{m}$ horizontal bubble diameter, $\mathrm{m}$ vertical bubble diameter, $m$ dimensionless constant, see eq. (9), dimensionless

$\bar{g} \quad$ gravitational force per unit mass, $\mathrm{m} / \mathrm{s}^{2}$

$h_{m f} \quad$ bed height at minimum fluidization conditions, $m$ 


\begin{tabular}{|c|c|}
\hline$I$ & unit tensor, dimensionless \\
\hline$M$ & molecular weight, $\mathrm{kg} / \mathrm{kmol}$ \\
\hline $\bar{n}$ & $\begin{array}{l}\text { unit outward normal vector, dimension- } \\
\text { less }\end{array}$ \\
\hline$n_{b}$ & bubble frequency, $1 / \mathrm{s}$ \\
\hline$p$ & pressure, $\mathrm{Pa}$ \\
\hline$p_{s}$ & solid pressure, $\mathrm{Pa}$ \\
\hline$Q$ & gas flow rate through orifice, $\mathrm{m}^{3} / \mathrm{s}$ \\
\hline$R_{b}$ & bubble radius, $m$ \\
\hline$R$ & gas constant, $\mathrm{J} / \mathrm{kmol} \mathrm{K}$ \\
\hline$R e_{p}$ & particle Reynolds number, dimensionless \\
\hline$S$ & $\begin{array}{l}\text { distance of bubble centre to gas distribu- } \\
\text { tor plate, } \mathrm{m}\end{array}$ \\
\hline$S_{a}$ & $\begin{array}{l}\text { source term in mass conservation equa- } \\
\text { tion of species } a, \mathrm{~kg} / \mathrm{m}^{3} \mathrm{~s}\end{array}$ \\
\hline$t$ & time, $\mathrm{s}$ \\
\hline$t_{b}$ & bubble formation time, $\mathrm{s}$ \\
\hline$T$ & temperature, $\mathrm{K}$ \\
\hline $\bar{u}$ & fluid-phase velocity, $\mathrm{m} / \mathrm{s}$ \\
\hline$u_{m f}$ & minimum fluidization velocity, $\mathrm{m} / \mathrm{s}$ \\
\hline$u_{o}$ & $\begin{array}{l}\text { superficial injection velocity through ori- } \\
\text { fice, } \mathrm{m} / \mathrm{s}\end{array}$ \\
\hline$U_{e}$ & $\begin{array}{l}\text { superficial leakage velocity of gas } \\
\text { through bubble boundary, } \mathrm{m} / \mathrm{s}\end{array}$ \\
\hline $\bar{v}$ & solid-phase velocity, $\mathrm{m} / \mathrm{s}$ \\
\hline$V_{b}$ & bubble volume, $\mathrm{m}^{3}$ \\
\hline$x$ & coordinate $x$-direction, $\mathrm{m}$ \\
\hline$x_{a}$ & $\begin{array}{l}\text { mass fraction of species } a \text { in the gas } \\
\text { phase, dimensionless }\end{array}$ \\
\hline$y$ & coordinate $y$-direction, $\mathrm{m}$ \\
\hline$y_{\mathfrak{a}}$ & $\begin{array}{l}\text { molar fraction of species } a \text { in the gas } \\
\text { phase, dimensionless }\end{array}$ \\
\hline$z$ & coordinate $z$-direction, $\mathrm{m}$ \\
\hline
\end{tabular}

\section{Greek letters}

$\beta$

$\delta_{b}$

$\delta x \quad$ computational cell dimension $x$-direc-

$\delta y$

$\delta z$

$\varepsilon$

$\left.\varepsilon_{m}\right\}$

$\lambda_{p}$

$\mu$

$\rho$

$\phi_{s}$

$\Psi(t)$

\section{Subscripts}

$a$

$b$

$e$

$f$

$h$

l

$m$ volumetric interphase momentum transfer coefficient, $\mathrm{kg} / \mathrm{m}^{3} \mathrm{~s}$

bed thickness, $\mathrm{m}$ tion, $m$

computational cell dimension $y$-direction, $m$

computational cell dimension $z$-direction, $m$

porosity, dimensionless

minimum fluidization porosity, dimensionless

slip parameter, $\mathrm{m}$

shear viscosity, $\mathrm{kg} / \mathrm{m} \mathrm{s}$

density, $\mathrm{kg} / \mathrm{m}^{3}$

sphericity, dimensionless

integral leakage fraction, dimensionless

species $a$

bed, bubble, species $b$, bottom

equivalent, emulsion phase

fluid phase

horizontal

left

gas-solid mixture

$\begin{array}{ll}m f & \text { minimum fluidization conditions } \\ o & \text { microscopic property, orifice } \\ p & \text { particle } \\ r & \text { right } \\ s & \text { solid phase } \\ t & \text { top } \\ v & \text { vertical } \\ x & x \text {-direction } \\ y & y \text {-direction } \\ z & z \text {-direction } \\ 0 & \text { freedom conditions }\end{array}$

Superscripts

- $\quad$ vector quantity

$T \quad$ transpose

Operators

$\nabla \quad$ gradient

$\nabla$ divergence

\section{REFERENCES}

Caram, H. S. and Hsu, K. K., 1986, Bubble formation and gas leakage in fluidized beds. Chem. Engng Sci. 41, 1445-1453.

Davidson, J. F. and Harrison, D., 1963, Fluidized Particles. Cambridge University Press, Cambridge, U.K.

Davidson, J. F. and Schüler, B. O. G., 1960, Bubble-formation at an orifice in an inviscid liquid. Trans Instn Chem. Engrs 38, 335-342.

Ding, J. and Gidaspow, D., 1990, A bubbling fluidization model using kinetic theory of granular flow. A.I.Ch.E. J. 36, 523-538.

Ding, J. and Lyczkowski, R. W., 1992, Three-dimensional kinetic theory modeling of hydrodynamics and erosion in fluidized beds. Powder Technol. 73, 127-138.

Gidaspow, D., 1986, Hydrodynamics of fluidization and heat transfer: supercomputer modelling. Appl. Mech. Rev. 39, $1-15$.

Gidaspow, D. and Ettehadieh, B., 1983, Fluidization in twodimensional beds with a jet; part 2: hydrodynamic modelling. Ind. Engng Chem. Fundam. 22, 193-201.

Harrison, D. and Leung, L. S., 1961, Bubble formation at an orifice in a fluidized bed. Trans Instn Chem. Engrs 39, 409-414.

Hoomans, B. P. B., Kuipers, J. A. M., Briels, W. J. and van Swaaij, W. P. M., 1996, Discrete particle simulation of bubble and slug formation in a two-dimensional gas fluidized bed: a hard sphere approach. Chem. Engng Sci. 51, 99-118.

Kuipers, J. A. M., Prins, W. and van Swaaij, W. P. M., 1991, Theoretical and experimental bubble formation at a single orifice in a two-dimensional gas-fluidized bed. Chem. Engng Sci. 46, 2881-2894.

Kuipers, J. A. M., van Duin, K. J., van Beckum, F. P. H. and van Swaaij, W. P. M., 1992, A numerical model of gasfluidized beds. Chem. Engng Sci. 47, 1913-1924.

Kuipers, J. A. M., van Duin, K. J., van Beckum, F. P. H. and van Swaaij, W. P. M., 1993, Computer simulation of the hydrodynamics of a two-dimensional gas-fluidized bed. Comput. Chem. Engng 17, 839-858.

Milne-Thomson, L. M., 1960, Theoretical Hydrodynamics, 4th Ed. Macmillan, London, U.K.

Nguyen, X. T. and Leung, L. S., 1972, A note on bubble formation at an orifice in a fluidized bed. Chem. Engng Sci. 27,1748 .

Nieuwland, J. J., Kuipers, J. A. M. and van Swaaij, W. P. M., 1995, Bubble formation in a two-dimensional gas-fluidized bed at elevated pressures, In Fluidization VIII, Tours.

Nieuwland, J. J., Veenendaal, M. L., Kuipers, J. A. M. and van Swaaij, W. P. M., 1996, Bubble formation at a single 
orifice in a two-dimensional gas-fluidized bed. Chem. Engng Sci. 51, 4087-4102.

Pierrat, P. and Caram, H. S., 1992, Bubble formation and gas leakage in beds at minimum fluidization conditions. In Fluidization VII (Edited by Potter, O. E. and Nicklin, D. J.) pp. 93-101. Engineering Foundation, New York, U.S.A

Rowe, P. N., MacGillivray, H. J. and Cheesman, D. J., 1979 , Gas discharge from an orifice into a gas-fluidized bed. Trans Instn Chem. Engrs 57, 194.
Yang, W. C., Revay, D., Anderson, R. G., Chelen, E. J., Keairns, D. L. and Cicero, D. C., 1984, Fluidization phenomena in a large-scale cold flow model, In Fluidization IV (edited by Kunii, D. and Toei, R.) pp. 77-85. Engineering Foundation, New York, U.S.A.

Yates, J. G., Rowe, P. N. and Cheesman, D. J., 1984, Gas entry effects in fluidized bed reactors. A.I.Ch.E. J. 30, 890-893

Zenz, F. A., 1968, Bubble formation and grid design. Inst Chem. Engng Symp. Ser. 30, 136-139. 